\title{
Short Term Consequences of Gallbladder Perforation with Bile and Gallstones Spillage during Laparoscopic Cholecystectomy
}

M.A.Abdlhakim, A.M.Zidan, S.G.Ibrahim and O.F.Ramadan

General Surgery Dept., Faculty of Medicine, Benha Univ., Benha, Egypt

E-Mail:omar@gmail.com

\begin{abstract}
Laparoscopic without drawbacks associated with two complications, bile duct injury and complications due to spillage of stone/bile within the peritoneal cavity. This study aimed to evaluation of different short-term complications of bile and gallstones spillage during laparoscopic cholecystectomy. This was a prospective comparative study carried on 100 patients, divided into 2 groups: group A :(50) control random doing laparoscopic cholecystectomy without gallbladder perforation ; group B:(50) cases doing laparoscopic cholecystectomy with gallbladder perforation and bile and gallstones spillage. The postoperative outcome was monitored during outpatient visits. The amount and nature of drained fluid were recorded daily. Postoperative complications including pain, peritonitis, and ileus were recorded. We used $3^{\text {rd }}$ generation cephalosporin for therapy of infection, and. Wound dressing was standard in all groups. Perforation Group was significantly longer than nonperforating group regard Duration of post-operative pain while regard Duration of post-operative ileus it was longer also in perforating group but not significantly. Perforation Group was significantly associated with Bile and stone spillage, abdominal collection and Re operate to treat complications, regard Converted to open surgery and Port site infection they were also associated with Perforation Group but not significantly. Intraoperative spillage of bile and gallstones during laparoscopic cholecystectomy can cause more postoperative pain,increase operative time,ileus and port site infection,which consequently increase the total time of hospitalization, inderminig.
\end{abstract}

Keywords: Gallbladder Perforation, Gallstones Spillage, Laparoscopic Cholecystectomy.

\section{Introduction}

The advantages of laparoscopic over open cholecystectomy are many as reported throughout the world and includes less post operative pain, earlier return of bowel function, shorter length of hospital stay, earlier return to full activity, improved cosmesis and decreased overall cost[1].

Laparoscopic cholecystectomy is however not without drawbacksTwo operative complications occur, bile duct injury and complications due to spillage of stone/bile within the peritoneal cavity are reported to occur with greater frequency during laparoscopic cholecystectomy[2].

Several studies have shown show that the incidence of spilled gallstones during laparoscopic cholecystectomy is about $5-40 \%$ of the surgeries performed, while incidence of stone loss is unknown [3].Early reports on laparoscopic cholecystectomy stated that stones left in the peritoneal cavity had no deleterious effect [4].

Although the incidence of spilt gallstones and their complications are low, they are of large variety [5].Thus, it makes a significant problem. The variety of complications caused by lost gallstones may range from simple surgical site infection to more serious forms like enterovesical fistula[4].

The incidence of complications related to spillage of gall-stonesduring laparoscopic cholecystectomy as per international data rangesbetween 2.3 and $7 \%$. This incidence increases by greater than two foldwhen the stones are unretrieved[6].

Although most surgeons regard spilled intraperitoneal gall stones asinconsequential, fever, ileus, Postoperative peritonitis, adhesions, intra and extra abdominal abscesses, biliary, enterocutaneous and enterovesical fistula formation have been documented[7].

In our study we determined to find the short term consequences of bile and gallstones spillage during laproscopic cholecystectomy.

\section{Patient and method}

This was a prospective comparative study carried on 100 patients, divided into 2 groups: group A:(50) control random doing laparoscopic cholecystectomy without gallbladder perforation; group B:(50) cases doing laparoscopic cholecystectomy with gallbladder perforation and bile and gallstones spillage.

\section{Inclusion criteria}

Patients with calcular cholecystitis in General Surgery Department who planned for laparoscopic cholecystectomy.

\subsection{Exclusion criteria}

- Patients had any complication during surgery or biliary leakage rather than bladder perforation.

- Patient with gallbladder abscess.

- Patients with acute pancreatitis.

- Patients who have alterations in blood clotting.

- Patient with CBD stones or during surgery.

- Patients with previous upper abdominal surgery.

The postoperative outcome was monitored during outpatient visits. The amount and nature of drained fluid were recorded daily. The drain was removed when the amount of fluid became less than $50 \mathrm{cc} / 24$ hours, or when the drained fluid started to become infected disregarding the amount drained in the last days. Time of drain removal postoperatively was recorded in each case. 
Postoperative complications including pain, peritonitis, and ileus were recorded. We used $3^{\text {rd }}$ generation cephalosporin for therapy of infection, and. Wound dressing was standard in all groups.

\subsection{Parameters of evaluation}

- Characteristics of patients concerning the age, co morbidities.

- Operative features including: size of bladder, hard or easy dissection,number of stones unretrived.

- Total amount of drained fluid, amount of drained fluid in the last 3 days, amount of fluid in the last day before drain removal, and timing of drain removal postoperatively.

- Clinical examination for evidence of port site infection.

- Radiological examination for any abdominal collection or peritonitis.

- In this study, we compare between laparoscopic cholecystectomy with or without gallbladder perforation and bile and stone spillage and detecting the complications either pain or ileus or peritonitis or abdominal collections.

The collected data were analyzed by computer using Statistical Package of Social Services version 24 (SPSS), Data were represented in tables and graphs, Continuous Quantitative variables e.g. age were expressed as the mean \pm SD \& median (range), and categorical qualitative variables were expressed as absolute frequencies (number) \& relative frequencies (percentage).

\section{Results}

Age was distributed as $42.28 \pm 10.54$ and $42.50 \pm 10.73$ with no significant difference between group regard sex distribution there was no significant difference between groups and majority of both groups were male

The present study shows that there was no significant difference between studied groups and most prevalent comorbidities was DM. The present study shows that there was no significant difference between studied groups

The present study shows that there was no significant difference between studied groups regard distribution of site. Perforation Group was significantly higher than non-perforating group. Perforation Group was significantly longer than non-perforating group regard both Duration of surgery \& Duration of hospital stay

Perforation Group was significantly longer than non-perforating group regard Duration of post-operative pain while regard Duration of post-operative ileus it was longer also in perforating group butnot significantly

Perforation Group was significantly associated with Bile and stone spillage, Abdominal collection and Re operate to treat complications, regard Converted to open surgery and Port site infection they were also associated with Perforation Group but not significantly

Table (1) Duration of surgery and Duration of hospital stay distribution between studied groups.

\begin{tabular}{lcccc}
\hline & Perforation Group & Non perforation Group & $\mathbf{t}$ & P \\
\hline Duration of surgery /minutes & $62.76 \pm 11.97$ & $51.08 \pm 8.14$ & 5.703 & $0.00^{* *}$ \\
Duration of hospital stay/ day & $1.54 \pm 0.51$ & $1.20 \pm 0.39$ & 2.956 & $0.004^{*}$ \\
\hline
\end{tabular}

Table (2) Duration of surgery and Duration of hospital stay distribution between studied groups.

\begin{tabular}{lllll}
\hline & Perforation Group & Non perforation Group & t & P \\
\hline Duration of post-operative pain/ days & $7.86 \pm 2.60$ & $4.38 \pm 1.35$ & 3.105 & $0.002^{*}$ \\
Duration of post-operative ileus/ day & $1.24 \pm 0.33$ & $1.10 \pm 0.37$ & 0.787 & 0.433 \\
\hline
\end{tabular}

Table (3) outcome and complication distribution between studied groups.

\begin{tabular}{|c|c|c|c|c|c|c|}
\hline \multirow{4}{*}{$\begin{array}{l}\text { Bile and stone } \\
\text { spillage }\end{array}$} & \multirow{4}{*}{$-\mathrm{VE}$} & \multirow{4}{*}{$\begin{array}{l}\mathrm{N} \\
\%\end{array}$} & \multicolumn{2}{|c|}{ Group } & \multirow[t]{2}{*}{$\mathrm{X}^{2 \text { Fisher exact }}$} & \multirow[t]{2}{*}{$\mathbf{P}$} \\
\hline & & & \multirow{2}{*}{$\begin{array}{c}\text { Perforation Group } \\
45\end{array}$} & \multirow{2}{*}{$\begin{array}{c}\text { Non perforation Group } \\
50\end{array}$} & & \\
\hline & & & & & & \\
\hline & & & $90.0 \%$ & $100.0 \%$ & & \\
\hline & $+\mathrm{VE}$ & $\mathrm{N}$ & 5 & 0 & 4.86 & $0.042 *$ \\
\hline & & $\%$ & $10.0 \%$ & $0.0 \%$ & & \\
\hline \multirow{2}{*}{$\begin{array}{l}\text { Converted to open } \\
\text { surgery }\end{array}$} & $-\mathrm{VE}$ & $\mathrm{N}$ & 46 & 50 & & \\
\hline & & $\%$ & $92.0 \%$ & $100.0 \%$ & & \\
\hline \multirow{6}{*}{$\begin{array}{l}\text { Abdominal } \\
\text { collection }\end{array}$} & $+\mathrm{VE}$ & $\mathrm{N}$ & 4 & 0 & 3.16 & 0.071 \\
\hline & & $\%$ & $8.0 \%$ & $0.0 \%$ & & \\
\hline & $-\mathrm{VE}$ & $\mathrm{N}$ & 42 & 50 & & \\
\hline & & $\%$ & $84.0 \%$ & $100.0 \%$ & & \\
\hline & $+\mathrm{VE}$ & $\mathrm{N}$ & 8 & 0 & 8.69 & $0.003 *$ \\
\hline & & $\%$ & $16.0 \%$ & $0.0 \%$ & & \\
\hline Port site infection & $-\mathrm{VE}$ & $\mathrm{N}$ & 41 & 47 & & \\
\hline
\end{tabular}




\begin{tabular}{|c|c|c|c|c|c|c|}
\hline & & $\%$ & $82.0 \%$ & $94.0 \%$ & & \\
\hline & $+\mathrm{VE}$ & $\mathrm{N}$ & 9 & 3 & 3.40 & 0.065 \\
\hline & & $\%$ & $18.0 \%$ & $6.0 \%$ & & \\
\hline \multirow{4}{*}{$\begin{array}{l}\text { Re operate to } \\
\text { treat } \\
\text { complications }\end{array}$} & $-\mathrm{VE}$ & $\mathrm{N}$ & 43 & 50 & & \\
\hline & & $\%$ & $86.0 \%$ & $100.0 \%$ & & \\
\hline & $+\mathrm{VE}$ & $\mathrm{N}$ & 7 & 0 & 7.52 & $0.006^{*}$ \\
\hline & & $\%$ & $14.0 \%$ & $0.0 \%$ & & \\
\hline \multirow[t]{2}{*}{ Total } & & $\mathrm{N}$ & 50 & 50 & & \\
\hline & & $\%$ & $100.0 \%$ & $100.0 \%$ & & \\
\hline
\end{tabular}

\section{Discussion}

In this study the results shows that age of patients with no perforation of gallbladder group $\mathrm{A}$ is ranging from 20-60 years old with mean $42.50 \pm 10.73$ years old and $70 \%$ of them are female while age of patient in Group B with gallbladder perforation is $42.28 \pm 10.54$ years old, ranged from $20-60$ years old, with no significant difference between group regard sex distribution there was no significant difference between groups and majority of both groups were female

In this study the results show that there was no significant difference between studied groups and most prevalent comorbidities was DM

In this study the results show that there is no significant difference between both groups regarding comorbidities where $54 \%$ of the studied Group A were has no comorbidities while $32 \%$ of group B has no comorbidites and $28 \%$ of them were diabetics, while $38 \%$ of patients in the Group B were diabetics.

In other study the results show that about $19 \%$ of them were diabetic in group A, while about $29 \%$ in group B were diabetic[8].

In this study the results show that $8 \%$ of group A patients with no perforation had elevation of liver enzymes before operation versus $18 \%$ of group B patients with perforation.

In other study the results show that $5 \%$ of group A patients with no perforation had elevation of liver enzymes before operation versus $15 \%$ of group B patients with perforation[9].

In this study the results show that CBD caliber in Perforation Group was significantly higher than nonperforating group

In this study the results show that mean of time of operation among Group A is $51.08 \pm 8.14$ minutes. While in Group B mean of time of operation is significantly higher with $62.76 \pm 11.97$ minutes.

In other study he results show that mean of time of operation among Group A is $45.07 \pm 6.18$ minutes. While in Group B mean of time of operation is significantly higher with $57.43 \pm 9.78$ minutes[10].

In this study the results show that mean of time of hospital stay among Group A is $1.20 \pm 0.39$ day. While in Group B mean of time of hospital stay is significantly higher with $1.54 \pm 0.51$ day.

In other study he results show that mean of time of hospital stay among Group A is $1.10 \pm 0.24$ day. While in Group B mean of time of hospital stay is significantly higher with $1.34 \pm 0.38$ day[10].
In this study the results show that mean of time of postoperative pain among Group A is $4.38 \pm 1.35$ day. While in Group B mean of time of postoperative pain is significantly longer with $7.86 \pm 2.60$ day.

In this study the results show that mean of time of postoperative ileus among Group A is $1.10 \pm 0.37$ day. While in Group B mean of time of postoperative ileus is longer with $1.24 \pm 0.33$ day but not significant.

In other study the results show that time of postoperative pain and ileus among in Group A(with no perforation) significantly higher than Group B (with perforation)[11].

In this study post-operative complications shows high statistically significant difference between both groups where pain, ileus, abdominal collections,port site infection and were more statistically higher in Group B.

Abdominal collection occours in $16 \%$ in group B while in group A were about $0 \%$. Port site infection in group B about $18 \%$ while in groupA were about $3 \%$.

Perforation Group was significantly associated with Bile and stone spillage, Abdominal collection and Re operate to treat complications, regard Converted to open surgery they were also associated with Perforation Group but not significantly.

\section{Conclusion}

Intraoperative spillage of bile and gallstones during laparoscopic cholecystectomy can cause more postoperative pain,increase operative time,ileus and port site infection, which consequently increase the total time of hospitalization, inderminig. The advantages of laparoscopic cholecystectomy.based on these interesting results,surgeons should make every effort to prevent gallbladder perforation by performing careful and precise dissection during the operation.

\section{References}

[1] S.Lim, S.Ghosh, P.Niklewski, S.Roy. Laparoscopic suturing as a barrier to broader adoption of laparoscopic surgery. JSLS: J., the Society of Laparoendoscopic Surgeons. Vol. 21,PP.(3),2017.

[2] Y.E.Altuntas, M.Oncel, M.Haksal. Gallbladder perforation during elective laparoscopic cholecystectomy: Incidence, risk factors, and outcomes. Northern clinics Istanbul.Vol. 5(1),PP.47,2018.

[3] A.A.MEMON, T.MAHESHWARI, LAL. complications of laparoscopic cholecystectomy in 
acute

Channel.Vol.19,PP.(2),2013.

[4] G.Nuzzo, F.Giuliante , F. Ardito. Complications of Laparoscopic Cholecystectomy". In: Biliary lithiasis, basic science, current diagnosis and management". By Borzellino G and Cordiano C. Springer. 2nd edition, Chapter.Vol. 21,PP.255311,2008 .

[5] B.Krishna. "Management of complications of laparoscopic cholecystectomy", In: Comprehensive laparoscopic surgery. By Ajav Kriplani. Indian Association of Gastro Intestinal Surgeons. Chapter.Vol. 12,PP. 95:99,2007.

[6] W.Kondo, N.Bourdel, B.Cotte. Does prevention of intraperitoneal spillage when removing a dermoid cyst prevent granulomatous peritonitis? BJOG.Vol.117(8),PP.1027-1030,2010.

[7] M.Khan , M.Aziz , "Experience in laparoscopic cholecystectomy". Mymensingh Med J.Vol. 19,PP.77-84,2010.
[8] M.A.Memon, R.K.Deeik, T.R.Maffi, R.J.Fitzgibbons. The outcome of unretrieved gallstones in the peritoneal cavity during laparoscopic cholecystectomy. Surg. Endosc.Vol.13,PP. 848-57,2013.

[9] D.C.Rice, M.A.Memon, R.L.Jamison .Long term consequences of intraoperative spillage of bile and gall stones during laparoscopic cholecystectomy. J. Gastrointest. Surg.Vol.1,PP.22,2012.

[10] G.Marakis, T.Pavlidis, F.Aimonioton. "Major complications during laparoscopic cholecystectomy". Int Surg .Vol.92,PP. 142146,2007.

[11]A. J.Nooghabi, M.Hassanpour, A.Jangjoo. Consequences of lost gallstones during laparoscopic cholecystectomy: a review article. Surgical Laparoscopy Endoscopy \& Percutaneous Techniques, Vol.26(3), PP.183-192,2016. 